\title{
Abducens Nerve
}

National Cancer Institute

\section{Source}

National Cancer Institute. Abducens Nerve. NCI Thesaurus. Code C12665.

A cranial nerve that supplies motor impulses to the lateral rectus muscle of the eye. 